\title{
Inkjet-printed graphene electrodes for dye-sensitized solar cells
}

David Dodoo-Arhin, ${ }^{a, b}$ Richard C. T. Howe, ${ }^{a}$ Guohua Hu, ${ }^{a}$ Yinghe Zhang, ${ }^{\mathrm{c}}$ Pritesh Hiralal, ${ }^{d}$ Abdulhakeem Bello, ${ }^{e}$ Gehan Amaratunga, ${ }^{d}$ and Tawfique Hasan*,a

a Cambridge Graphene Centre, University of Cambridge, 9 JJ Thomson Avenue, Cambridge, CB3 0FA, UK.

${ }^{b}$ Department of Material Science and Engineering, University of Ghana, P. O. Box Lg 77, Accra-Legon, Ghana.

${ }^{c}$ Faculty of Science and Engineering, Waseda University, Tokyo, Japan.

${ }^{d}$ Department of Engineering, University of Cambridge, 9 JJ Thomson Avenue, Cambridge, CB3 0FA, UK.

${ }^{e}$ Department of Physics, University of Pretoria, Pretoria 0028, South Africa.

We present a stable inkjet printable graphene ink, formulated in isopropyl alcohol via liquid phase exfoliation of chemically pristine graphite with a polymer stabilizer. The rheology and low deposition temperature of the ink allow uniform printing. We use the graphene ink to fabricate counter electrodes (CE) for natural and ruthenium-based dye-sensitized solar cells (DSSCs). The repeatability of the printing process for the CEs is demonstrated through an array of inkjet-printed graphene electrodes, with $\sim 5 \%$ standard deviation in the sheet resistance. As photosensitizers, we investigate natural tropical dye extracts from Pennisetum glaucum, Hibiscus sabdariffa and Caesalpinia pulcherrima. Among the three natural dyes, we find extracts from C. pulcherrima exhibits the best performance, with $\sim 0.9 \%$ conversion efficiency using a printed graphene counter electrode and a comparable $\sim 1.1 \%$ efficiency using a platinum $(\mathrm{Pt})$ CE. When used with N719 dye, the inkjet-printed graphene CE shows a $\sim 3.0 \%$ conversion efficiency, compared to $\sim 4.4 \%$ obtained using Pt CEs. Our results show that inkjet printable graphene ink, without any chemical functionalization, offers a flexible and scalable fabrication route, with a material cost of only $\sim 2.7 \%$ of the equivalent solution processed Pt-based electrode.

*Corresponding author. e-mail: th270@cam.ac.uk (Tawfique Hasan) 


\section{Introduction}

Graphene has attracted significant interest in a variety of electronic and optoelectronic applications, including photovoltaics. This is because it can serve multiple purposes: as a transparent conducting electrode $[1,2]$, as a channel for charge transport [3] and as a counter electrode material [4]. It has been reported that the edge plane sites of graphene exhibit faster electron-transfer kinetics than the basal plane sites [5]. Thus, exfoliated graphene flakes/platelets may offer good electrocatalytic properties. Coupled with this, electrical conductivity and chemical stability makes graphene an attractive counter electrode material.

Graphene can be prepared via various top-down and bottom-up approaches; the most widely exploited ones being mechanical cleavage [6], chemical vapour deposition (CVD) [7], and solution based methods such as chemical exfoliation [8] and ultrasonic-assisted exfoliation (UALPE) [9-12]. Though micromechanically cleaved graphene is ideal for fundamental studies due to the high quality of the exfoliated material, the low yield of the process renders it unsuitable for large-scale applications [6]. In recent years, CVD has been scaled up to produce large-area, high quality graphene $[2,7]$ accompanied by a significantly improved understanding of the growth mechanisms and graphene-catalyst interaction [13], but the high temperature production process and subsequent transfer to target substrate is not always ideal for photovoltaic devices. In addition, CVD grown mono- or few-layer graphene has limited exposed edges, a key requirement for enhanced electrocatalytic properties [5, 14]. Solution processing, meanwhile, allows scalable production of dispersions consisting of single- and few-layer graphene flakes under ambient conditions [9-12]. These can be used as inks using existing functional printing and coating techniques, enabling graphene to be deposited onto substrates such as silicon and glass as well as flexible materials [15-18]. Inkjet printing is of particular interest, allowing additive patterning, direct writing without the use of masks or stencils and low cost $[15,17$, 19].

Amongst the different photovoltaic devices, dye-sensitized solar cells (DSSCs) offer certain advantages, including low cost materials [20, 21], economic fabrication, good low-light conversion efficiencies $(>12 \%)$ and many colour design possibilities [22, 23]. The DSSC structure consists of a $\sim 10 \mu \mathrm{m}$ thick mesoporous network of nanocrystalline semiconductor oxide (e.g. titanium dioxide, $\mathrm{TiO}_{2}$ ) deposited onto a 
conducting electrode or transparent conducting electrode (e.g. FTO, ITO etc), and an electrolyte. The porous network of nanocrystals $(10-30 \mathrm{~nm})$ provides the large surface area necessary for adsorption of a thin layer of dye molecules, typically a ruthenium(II) bipyridyl dye [24] or an organic dye [21, 25, 26], to allow for optimum light harvesting. Absorption of light by a dye molecule creates an excited molecular electronic state. The dye rapidly returns to its original oxidation state via electron transfer from iodide ions in the $\mathrm{I}^{-} / \mathrm{I}_{3}{ }^{-}$redox electrolyte. The $\mathrm{I}_{3}{ }^{-}$ions formed by oxidation of $\mathrm{I}^{-}$diffuse a short distance $(<50 \mu \mathrm{m})$ through the electrolyte to the cathode, which is coated with a thin layer of platinum catalyst, where the regenerative cycle is completed by electron transfer to reduce $\mathrm{I}_{3}{ }^{-}$to $\mathrm{I}^{-}$[27].

Two of the most important factors which influence the performance of a DSSC are the dye used as a sensitiser, and the counter-electrode material. The key properties of the dye are the absorption across the solar spectrum and the adsorption/adhesion of the dye molecules to the surface of the semiconductor oxide [28]. The most widely used sensitizers are those based on heavy transition metal co-ordination compounds (e.g. ruthenium $(\mathrm{Ru})$ polypyridyl complexes) $[23,29]$ due to their efficient metal-to ligand charge transfer, intense charge-transfer absorption across the visible range and long excited lifetime [23]. However, Ru-polypyridyl based complexes are expensive $(\sim 1200 \$ / g)$ [30], and contain a heavy rare earth metal, which is environmentally undesirable [31]. Thus, investigation into environmentally-friendly, economic and readily available dyes, including those extracted from plants, remains a strong interest $[21,25,26,32,33]$.

Dyes produced from plant extracts are advantageous due to their wide availability, simple extraction process, usability without further purification, environmental sustainability, and low cost [21, 25, 26, 32, 33]. Anthocyanin molecules (water-soluble vacuolar pigments [34]) are found in tissues of higher plants (i.e. land plants that have lignified tissues or xylems for transporting water and minerals throughout the plant), and are responsible for their red-blue range of pigments, depending on $\mathrm{pH}[21,25,26$, 32-36]. Anthocyanin molecules contain carbonyl and hydroxyl groups, which can adsorb on to the surface of porous $\mathrm{TiO}_{2}$ films, leading to photoelectron transfer from the anthocyanin molecule to the conduction band of $\mathrm{TiO}_{2}[21]$.

The counter-electrode, meanwhile, should be catalytically active and electrically conducting. It should also exhibit a low over-potential for rapid reduction of the redox couple to carry the generated photocurrent across the width of the solar cell. Platinum 
(Pt) is the most commonly used counter electrode material in DSSCs [37]. However, while the required platinum loading for optimum performance of the solar cell is small $\left(\sim 3.2 \mathrm{~g} / \mathrm{m}^{2}\right)[38,39]$, the dissolution of the platinum film in the corrosive $\mathrm{I}_{3}^{-} / \mathrm{I}^{-}$ electrolyte and high-temperature heat treatment $\left(\sim 300-400{ }^{\circ} \mathrm{C}\right)[37,40]$ required for good Pt-substrate adhesion limits their use on flexible substrates and in low-cost applications. This has necessitated the search for chemically stable and cost-effective counter-electrode materials for DSSCs such as various carbon nanomaterials [14, 4146] conductive organic polymers [47] and inorganic semiconductors [48]. In this context, graphene has emerged as a promising low-cost electrode material candidate, which provides both the conductive pathways and catalytic properties [41-43, 49-54]. The performance of DSSCs with a graphene counter electrode is dependent on the structure of graphene. Although CVD graphene produces continuous layers with high electrical conductivity and comparable charge transfer resistance $\left(R_{c t}\right)$ to platinum [54], it has a very limited number of active sites for $\mathrm{I}^{-} / \mathrm{I}_{3}{ }^{-}$electrocatalysis [55]. On the other hand, single and few-layer graphene nano-flakes obtained via solution processing have high density of active edge sites, offering high catalytic activity, and modest electrical conductivity $[15,17,18]$ at a fraction of the cost. In addition, solution processed graphene can be used in combination with a variety of deposition technologies (such as inkjet [15-18, 56], screen printing [42], spray coating [17, 44] or flexographic printing [43]) forming a versatile platform not only for DSSCs but also for any devices requiring such electrode materials for large scale fabrication. We note that there have been reports in the literature of graphene inks being used for DSSCs [14, 41-43]. However, these typically use functionalised forms of graphene such as graphene oxide [41-43]. While the presence of functional groups on graphene sheets can aid their exfoliation and dispersion into solvents, the electrical properties of the material are compromised, and cannot be fully restored to those of pristine graphene [57].

Here, we present formulation of an inkjet printable pristine graphene ink for the fabrication of graphene-based counter electrodes as a Pt alternative. Through the use of a polymer stabiliser, we tune the rheology of the ink, allowing stable and repeatable CE printing. We also investigate three natural tropical dye extracts as photosensitizers as a low-cost alternative to standard Ru-based dyes. We demonstrate that with only $\sim 2.7 \%$ of the materials cost of platinum our printed graphene counter electrode, 
without any structural or chemical optimization, shows comparable performance to $\mathrm{Pt}$ CEs with both natural and Ru-based dyes as sensitizers.

\section{Preparation and characterisation of natural dye sensitizer extracts}

\subsection{Extraction of natural dyes}

Clean, fresh specimens of H. sabdariffa, C. pulcherrima and P. glaucum are oven dried at $60{ }^{\circ} \mathrm{C}$ and crushed into fractionlets. To extract the natural dye into the solution, $5 \mathrm{~g}$ of each of these samples are put in $60 \mathrm{~mL}$ of ethanol for 5 days at room temperature without exposure to light. The dye solutions are then filtered to remove the solid residues. The concentration of the dye in the final solutions is $\sim 0.4 \mathrm{~g} / \mathrm{L}$.

\subsection{Characterisation of natural dyes}

Anthocyanins and their derivatives, which belong to a group of natural phenolic compounds, show a broad absorption band in the visible spectral range [21, 25]. This absorption band is due to charge transfer transitions from the highest occupied molecular orbital (HOMO) to the lowest unoccupied molecular orbital (LUMO) [58]. As such, the response of these dyes to light absorption is solvent and $\mathrm{pH}$ sensitive [34]. Indeed, anthocyanin molecules tend to show a red flavylium form in acidic medium and purple deprotonated quinonodial form as the solution $\mathrm{pH}$ increases [21, $34,59,60]$.

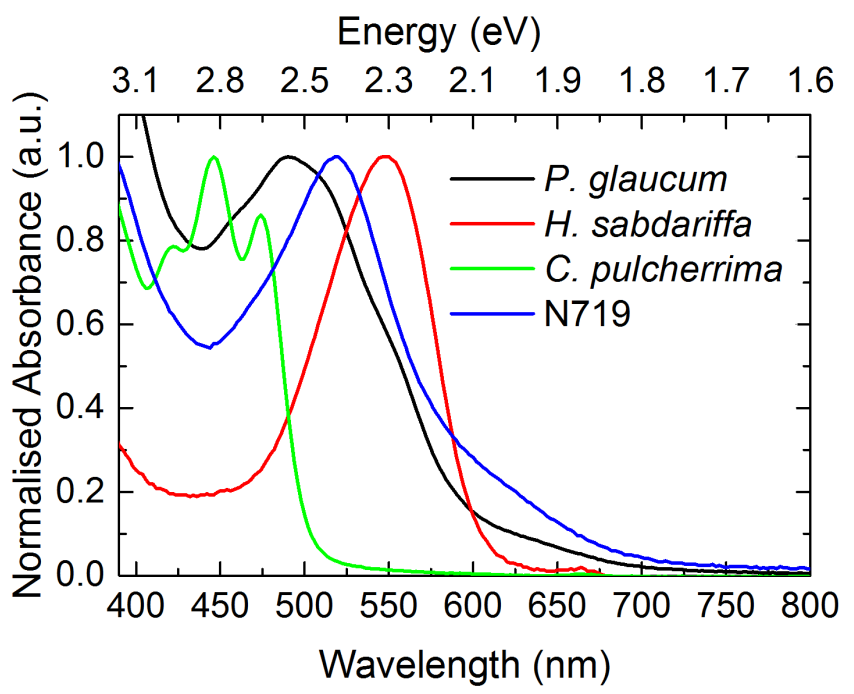

Figure 1 - Optical absorption spectra of the photosensitizers normalized to the highest absorbance peak 
Figure 1 shows representative vis-NIR absorption spectra of the natural dyes in ethanol. The absorbance peaks (C. pulcherrima: $\sim 422, \sim 446, \sim 474 \mathrm{~nm}$, P. glaucum: $\sim 492 \mathrm{~nm}, H$. sabdariffa: $\sim 548,666 \mathrm{~nm}$ ) are attributed to the presence of anthocyanin, carotene, flavone and xanthophyll molecules [61, 62]. We also carry out Fourier transform infrared spectroscopy (FTIR) to confirm the presence of various functional groups in the dye extracts, see Supplementary Information for details. For comparison, the inorganic ruthenizer 535-bisTBA (N719) dye, which is an outstanding solar light absorber and charge-transfer sensitizer, shows a broad absorption peak at $\sim 518 \mathrm{~nm}$, attributed to its metal to ligand charge transfer transition [23].

The dyes are then characterized by Cyclic Voltammetry (CV) to investigate corresponding HOMO and LUMO energy levels and their oxidation (removal of electron from HOMO energy level) and reduction (addition of electron to LUMO energy level) potentials. The onset potentials of oxidation and reduction of the dyes can be correlated to their electron affinity and ionization potential according to the empirical relationship proposed in Refs $[63,64]$ on the basis of comparisons between theoretical and experimental electrochemical measurements. CV measurements of the natural dyes are taken using a three-electrode electrochemical cell at $100 \mathrm{mVs}^{-1}$ constant scan rate under nitrogen atmosphere. A $1.6 \mathrm{~mm}$ diameter glassy carbon electrode is used as the working electrode, and a platinum wire as the auxiliary electrode. All potentials are measured and quoted against an $\mathrm{Ag} / \mathrm{AgCl}(3 \mathrm{M} \mathrm{KCl})$ electrode in a double bridge filled with $3 \mathrm{M} \mathrm{KCl}$ solution (upper part) and supporting electrolyte solution (lower part). CV measurements show distinct oxidation and reduction processes for all the three dyes as shown in Fig. 2. The curves on the forward and reverse scans indicate that they are diffusion controlled, and hence the electrode process is rapid and reversible $[63,64]$. Thus, the data from the forward and reverse processes can be used for the calculation of the thermodynamic parameters $[63,64]$. The estimated HOMO and LUMO energy levels of the dyes, determined from the oxidation and reduction peaks from the CV measurements are presented in Table 1. For comparison, the Ruthenizer 535-bisTBA (N719) dye, with typical absorption peak $\left(\lambda_{\max }\right)$ of $\sim 535 \mathrm{~nm}\left[\varepsilon / 10^{4} \mathrm{M}^{-1} \mathrm{~cm}^{-1}\right]$, has HOMO and LUMO levels of $5.34 \mathrm{eV}$ and $-3.43 \mathrm{eV}$, respectively [30]. 


\begin{tabular}{|c|c|c|c|c|}
\hline Dyes & $\mathbf{E}_{\mathbf{0 x}}(\mathbf{V})$ & $\mathbf{E}_{\text {red }}(\mathbf{V})$ & $\mathbf{I}_{\mathbf{p}}(\mathbf{H O M O})(\mathbf{e V})$ & $\mathbf{E}_{\mathbf{a}}(\mathbf{L U M O})(\mathbf{e V})$ \\
\hline C. pulcherrima & 0.2706 & -0.375 & -4.671 & -4.025 \\
\hline H. sabdariffa & 0.324 & -0.248 & -4.724 & -4.152 \\
\hline P. glaucum & 0.302 & -0.279 & -4.702 & -4.121 \\
\hline
\end{tabular}

Table 1 - Electrochemical band levels for the organic dyes

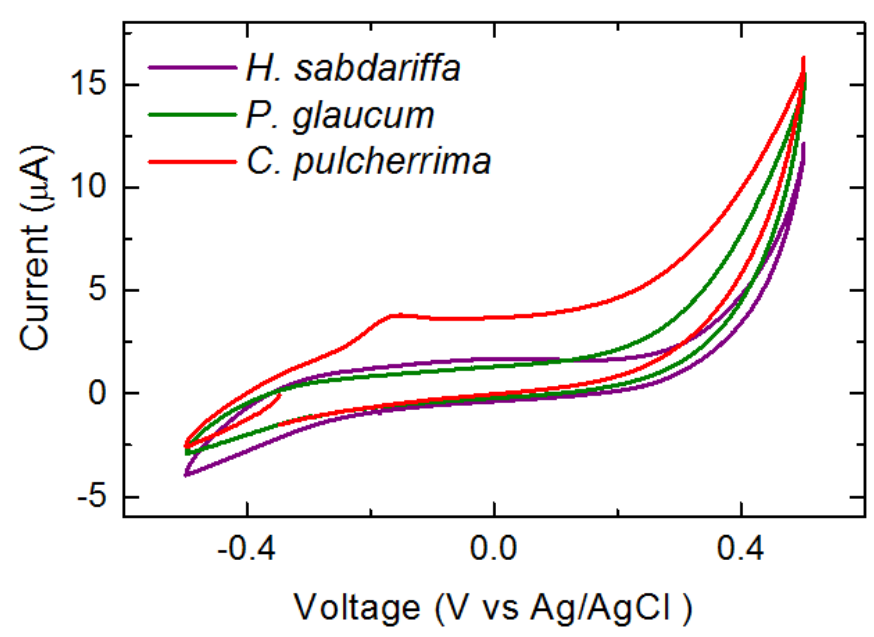

Figure 2 - Cyclic voltammograms of the natural dyes

\section{Preparation and characterisation of graphene inks}

\subsection{Graphene ink preparation}

The graphene ink is formulated from graphene prepared via ultrasonic-assisted liquid phase exfoliation (UALPE). In this process, bulk graphite flakes are mixed into a solvent, and the mixture is ultrasonicated. The ultrasound causes high-frequency pressure variations in the solvent, forming localised microcavities. These cavities are inherently unstable and rapidly collapse, producing high shear forces sufficient to overcome the weak interlayer van der Waals forces and exfoliate graphene flakes from the bulk crystal $[9,10]$. The graphene produced by this route is chemically pristine, since the UALPE process involves no chemical pre- or post-treatment. The exfoliation process, as well as the stability of the resultant dispersion, is dependent on the intermolecular interactions between the solvent and the graphene flakes. On a basic level, the exfoliation process can be explained in terms of surface energy [11, 12], 
although a more refined understanding can be gained from the Hansen solubility parameters (HSPs) [65, 66]. It was determined that the best suited solvents have dispersive $\left(\delta_{\mathrm{D}}\right)$, polar $\left(\delta_{\mathrm{P}}\right)$ and hydrogen bonding $\left(\delta_{\mathrm{H}}\right)$ parameters that match those experimentally derived for graphene $\left(\delta_{\mathrm{D}, \mathrm{Graphene}}=18 \mathrm{MPa}^{1 / 2}, \delta_{\mathrm{p}, \mathrm{Graphene}}=9.3 \mathrm{MPa}^{1 / 2}\right.$, $\left.\delta_{\mathrm{H}, \text { Graphene }}=7.7 \mathrm{MPa}^{1 / 2}\right) \quad$ [65]. However, the best suited solvents (e.g. Nmethylpyrollidone - NMP, cyclohexanone) typically present processing challenges due to their high boiling points (NMP $\sim 202{ }^{\circ} \mathrm{C}$, cyclohexanone $\sim 155{ }^{\circ} \mathrm{C}$ ), as well as poor wettability due to their high surface tension $\left(\mathrm{NMP} \sim 44.6 \mathrm{mNm}^{-1}\right.$, cyclohexanone $34.4 \mathrm{mNm}^{-1}$ ) [67].

For ease of processing, it would therefore be advantageous to develop graphene inks from low boiling-point solvents. Alcohols, in particular, are attractive as they additionally offer low surface tension $\left(\sim 20-25 \mathrm{mNm}^{-1}\right)$, allowing good wetting of the substrate [56, 68]. Indeed, they are commonly used as the primary or secondary solvent in the majority of graphics and functional inks [69]. Among the common alcohols, isopropyl alcohol (IPA) can exfoliate graphene with meta-stable dispersion [70] due to the mismatch in HSPs $\left(\delta_{\mathrm{D}}=15.8 \mathrm{MPa}^{1 / 2}, \delta_{\mathrm{P}}=6.1 \mathrm{MPa}^{1 / 2}, \delta_{\mathrm{H}}=15.4 \mathrm{MPa}^{1 / 2}\right)$ [65] compared to graphene. The poor long-term stability of a pure IPA based graphene dispersion means that it cannot be used for inkjet printing, as it will aggregate and block the printing nozzles. UALPE with ionic surfactants and nonionic polymers are commonly used strategies to stabilize graphene [9-11, 56, 71, 72]. In addition to stabilization, the addition of polymers offers modification of viscosity, allowing optimisation of the ink formulation for inkjet printing [19]. We use polyvinylpyrrolidone (PVP), a polymer analogy to NMP (PVP has N-substituted pyrrolidone rings similar to those of NMP) which has been used before to stabilize carbon nanostructures, such as nanotubes and graphene in different solvents [56, 72, 73].

To prepare the ink, $100 \mathrm{mg}$ of graphite flakes (Sigma-Aldrich, $100 \mathrm{mesh}$ ) with $1.5 \mathrm{mg}$ PVP (Sigma Aldrich, average molecular weight 10,000 Da) is ultrasonicated in $10 \mathrm{~mL}$ IPA for 12 hours at $\sim 15{ }^{\circ} \mathrm{C}$ using a low-power bath sonicator. This starting PVP concentration enables stabilization in addition to the desired ink rheological properties specific to our inkjet-printing nozzle $[17,19,56]$. Following sonication, the dispersion is centrifuged at $\sim 4000 \mathrm{rpm}(\sim 1500 \mathrm{~g})$ for 1 hour to remove the unexfoliated flakes. Finally, the ink is filtered via vacuum filtration (glass fiber filter, $1 \mu \mathrm{m}$ pore), removing any large particles that may otherwise clog the inkjet nozzles during the 
printing process [19]. The final ink (a photograph of which is shown as an inset to Fig. 3 , is stable, and forms no visible aggregates even over several months.

\subsection{Graphene ink characterisation}

The concentration of dispersed graphene may be estimated by considering the optical absorption of the ink, and using the Beer-Lambert law:

$A_{\lambda}=\alpha_{\lambda} l c$

where $c$ is the graphene concentration $\left(\mathrm{gL}^{-1}\right), l$ is the distance the light passes through the dispersion (m), and $A_{\lambda}$ and $\alpha_{\lambda}$ are the absorbance (a.u.) and material dependent optical absorbance coefficient $\left(\mathrm{Lg}^{-1} \mathrm{~m}^{-1}\right)$ at wavelength $\lambda(\mathrm{nm})$, respectively. Figure 3 shows the optical absorbance spectrum of the dispersion diluted to $10 \mathrm{vol} \%$ to reduce scattering losses during measurement, and with the background absorbance from the solvent and PVP subtracted [74]. The spectrum is mostly featureless as expected, due to the linear dispersion of Dirac electrons [75]. The peak in the UV region is a signature of the van Hove singularity in the graphene density of states [75]. Using $\alpha_{660 \mathrm{~nm}} \sim 2460 \mathrm{Lg}^{-1} \mathrm{~m}^{-1}[11]$, we estimate the concentration of graphene in the undiluted dispersion as $0.42 \mathrm{gL}^{-1}$.

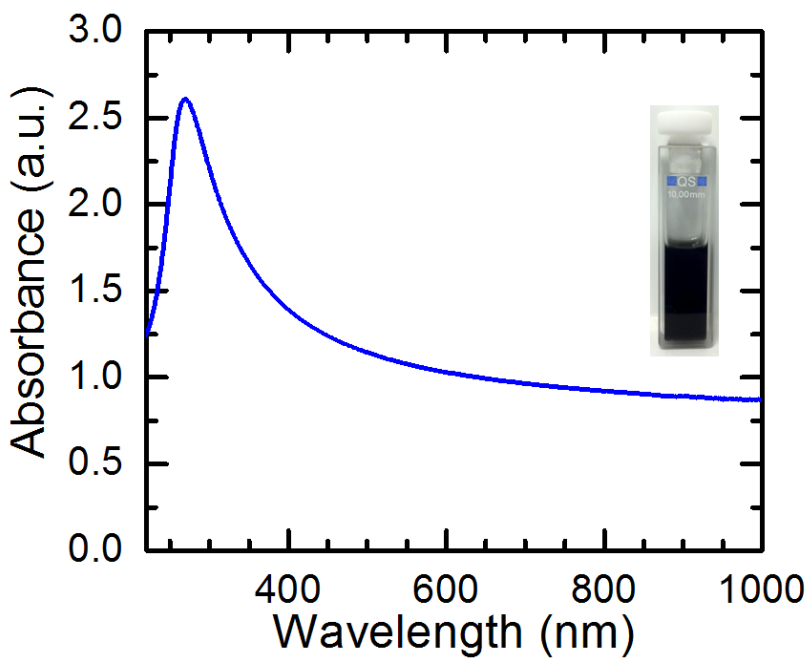

Figure 3 - Optical absorption spectrum of the graphene in dispersion diluted to $10 \mathrm{vol} \%$ to avoid scattering effects. Inset - photograph of a cuvette containing the as-prepared graphene ink

The dimensions of the exfoliated flakes are measured via atomic force microscopy (AFM). The as prepared ink is diluted to $5 \mathrm{vol} \%$ and drop-casted onto a $\mathrm{Si} / \mathrm{SiO}_{2}$ wafer. The sample is then annealed at $400^{\circ} \mathrm{C}$ for 30 minutes, sufficient to decompose any 
residual PVP [76] without affecting the graphene flakes [18, 77]. This gives isolated and polymer free flakes on the substrate, allowing accurate measurement of the flakes. The flakes are measured using a Bruker Dimension Icon AFM in ScanAsyst ${ }^{\mathrm{TM}}$ mode. The distributions of measured flake thicknesses and lateral dimensions are shown in Figure 4, along with the images of typical flakes. The average flake thickness is $(5.9 \pm$ 0.2 ) $\mathrm{nm}$, with $\sim 56 \%$ of flakes $\leq 4 \mathrm{~nm}$ thick (equivalent to $<10$ layers, assuming $\sim 0.7$ $\mathrm{nm}$ measured thickness for a monolayer flake and $\sim 0.35 \mathrm{~nm}$ increase for each subsequent layer) [78]. The average lateral dimension is $(196 \pm 6) \mathrm{nm}$. This gives a relatively high edge to surface area ratio of $\sim 1: 17$. The disordered sites at the edges of flakes act as active catalytic sites for the $\mathrm{I}^{-} / \mathrm{I}_{3}{ }^{-}$redox couple reaction to carry photocurrent across the width of the DSSC, making the as-produced graphene ink a potential counter electrode material for DSSCs.
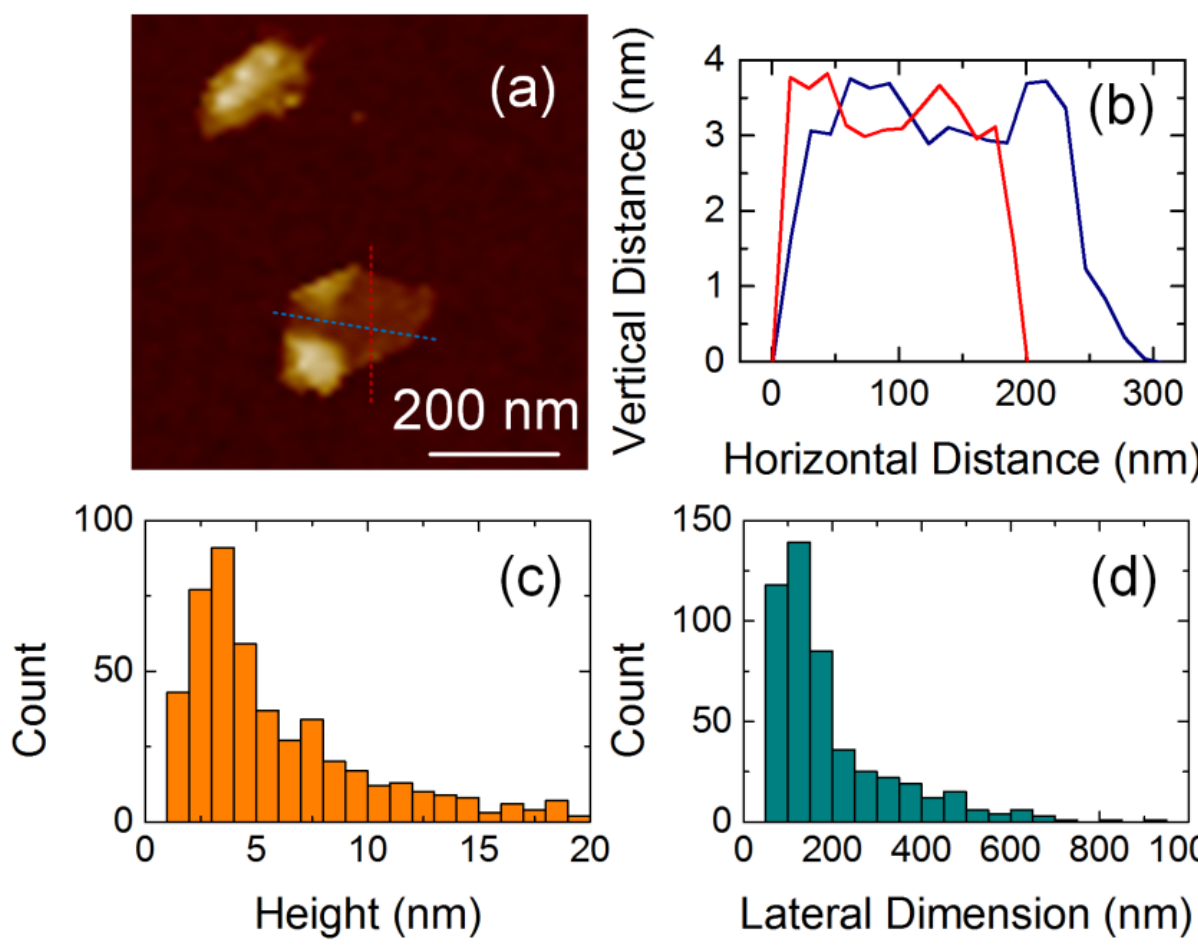

Horizontal Distance $(\mathrm{nm})$

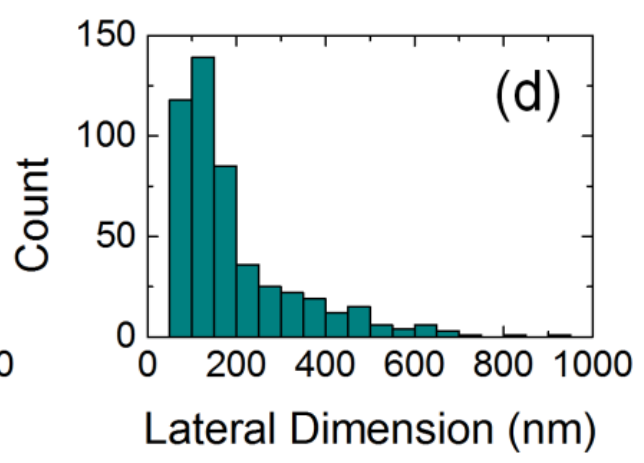

Figure 4 - AFM characterisation of the dispersed graphene flakes. (a) image and (b) section of a typical graphene flake. Distributions of (c) flake thickness and (d) flake lateral dimensions.

When formulating an ink for inkjet printing, various parameters of the ink govern the successful formation of droplets. First, the particle size (i.e. graphene flake dimensions) in the ink must be considered, as large particles in the ink can clog nozzles, or disrupt the ink flow [19]. The nozzle size of the DMP-2831 used in this 
work is $22 \mu \mathrm{m}$, significantly larger than the average flake dimension measured via AFM, confirming that nozzle clogging should not present any issues. Stable drop generation (single droplet generation for each electrical impulse, without the formation of satellite droplets) and jetting of ink (avoiding deviation of droplet trajectory) is of primary importance for high quality inkjet printing. Unstable jetting may lead to uncontrolled amount of ink deposition on to undesired locations. In inkjet printing, a figure of merit, $Z$, is commonly used to consider the printability of inks and is defined as: $Z=(\gamma \rho a)^{1 / 2} / \mu$ where, $\gamma$ is surface tension of the ink $\left(\mathrm{mNm}^{-1}\right), \rho$ is the density of ink $\left(\mathrm{gcm}^{-3}\right), \mu$ is the viscosity of the ink (mPas) and $a$ is the nozzle diameter $(\mu \mathrm{m})$. As a rule of thumb, it is commonly accepted that $1<Z<14$ is required for stable drop-ondemand inkjet printing [19]. Inks with $Z<1$ are too viscous for droplet ejection, while those with $\mathrm{Z}>14$ will produce satellite droplets in addition to the primary droplet, reducing printing reproducibility [19]. We stress that the range of $Z$ values should be considered as guide only. Inks with $Z$ values outside this range may also be printable, in particular, by controlling the shape and amplitude of the electrical pulses for droplet generation.

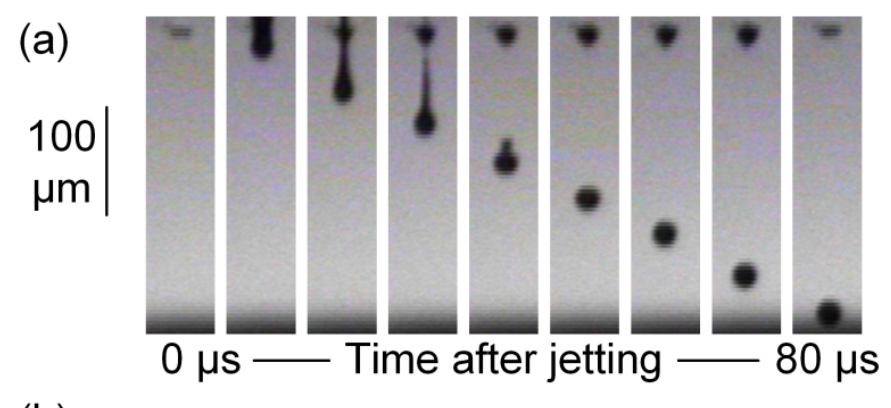

(b)

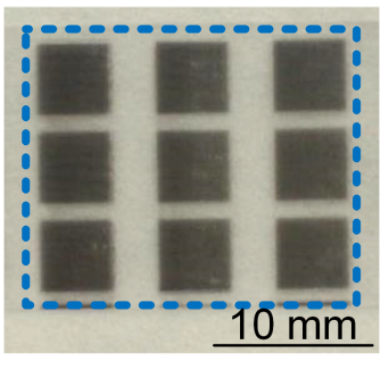

(c)

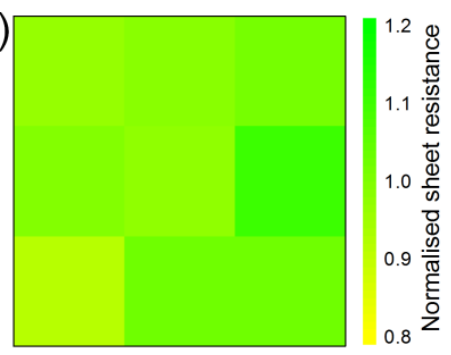

Figure 5 - Inkjet printing of graphene ink. (a) Jetting process of the ink, showing stable single droplet ejection. $(b, c)$ Printed graphene squares for printing consistency characterisation, showing photograph (b) and normalised sheet resistance (c) for the electrodes.

To determine the $Z$ value of the graphene-PVP in IPA ink, we measure $\gamma$ via a pendant droplet method, and $\mu$ using a parallel plate rheometer. Both the measurements are conducted at room temperature. We measure $\gamma \sim 28.0 \mathrm{mNm}^{-1}$ and $\mu \sim 2.3 \mathrm{mPas}$. The 
measured density of the ink is $\rho \sim 0.8 \mathrm{gcm}^{-3}$. With $a=22 \mu \mathrm{m}$, we calculate $Z \sim 9.6$, falling well into the recommended range for stable jetting. This is confirmed by experimental results, where we observe consistent single drop ejection for our ink; Fig. 5a. From the position of the droplet at different times after jetting, we calculate an average jetting speed of $(3.44 \pm 0.03) \mathrm{ms}^{-1}$.

We next confirm the uniformity of our print process by preparing an array of electrodes on a glass substrate. 9 squares of $6 \mathrm{~mm} \times 6 \mathrm{~mm}$ are printed at a platen temperature of $60^{\circ} \mathrm{C}$, as shown in Figure $5 \mathrm{~b}$. The printed squares are highly uniform, showing no coffee-ring effect. After printing, the samples are annealed at $400{ }^{\circ} \mathrm{C}$ for 30 minutes to remove residual PVP. The volume of ink printed is sufficient to achieve a conductive network of graphene flakes through the printed film (i.e. above the percolation threshold) [56]. The sheet resistance of the electrodes is measured for their consistency, as shown in Figure 5c. The printed electrodes show good electrical uniformity, with $<5 \%$ standard deviation in sheet resistance between them.

\section{DSSC fabrication and Photovoltaic characteristics}

\subsection{DSSC fabrication}

Fabrication of a DSSC involves several steps. First, two FTO (fluorine-doped $\mathrm{SnO}_{2}$ ) conductive glass substrates $(\sim 2 \mathrm{~cm} \times 2 \mathrm{~cm}, 8 \Omega / \square$, Solaronix $)$ are cleaned in a detergent solution using an ultrasonic bath for $10 \mathrm{~min}$, rinsed with deionised water and ethanol, followed by oven drying at $90{ }^{\circ} \mathrm{C}$. One of the FTO substrates is then immersed in a $40 \mathrm{mM}$ aqueous solution of $\mathrm{TiCl}_{4}$ (Sigma Aldrich) at $\sim 70{ }^{\circ} \mathrm{C}$ for $30 \mathrm{~min}$ (for good mechanical adhesion of the $\mathrm{TiO}_{2}$ ) and washed with deionised water and ethanol before drying.

The photoelectrode is prepared by depositing a $\sim 9 \mu \mathrm{m}$ thick $\mathrm{TiO}_{2}$ film of $\mathrm{TiO}_{2}$ paste (Solaronix) on to the $\mathrm{TiCl}_{4}$ treated FTO conductive glass substrate by doctor-blading. The active area is $\sim 0.25-0.36 \mathrm{~cm}^{2}$. The electrode is then gradually preheated over a period of $\sim 60$ minutes, and then sintered at $500{ }^{\circ} \mathrm{C}$ for $30 \mathrm{~min}$ in air. After cooling to $\sim 80{ }^{\circ} \mathrm{C}$, the $\mathrm{TiO}_{2}$ electrode is immersed in the dye-ethanol solution for $12-24 \mathrm{~h}$ at 50 ${ }^{\circ} \mathrm{C}$ under gentle magnetic stirring. Next, excess dye is washed away with anhydrous ethanol.

A standard, platinum based counter electrode is prepared by drop casting $\sim 60 \mu \mathrm{l}$ of $10 \mathrm{mM} \mathrm{H}_{2} \mathrm{PtCl}_{6}$-Isopropyl alcohol (Sigma Aldrich) solution onto the other FTO-glass 
substrate with pre-drilled holes at room temperature and then heating gradually to $\sim 450{ }^{\circ} \mathrm{C}$ for $30 \mathrm{~min}$. The graphene $\mathrm{CE}$ is prepared by inkjet printing the graphene ink on the pre-drilled FTO glass substrate at $60{ }^{\circ} \mathrm{C}$ platen temperature. The active graphene deposited area is $2.0 \mathrm{~cm} \times 1.5 \mathrm{~cm}$, leaving the edge for electrical contact. The substrate is gradually heated above $150{ }^{\circ} \mathrm{C}$ for $\sim 30$ mins to improve graphene adhesion, and to remove the polymer stabilizer. The relative costs of these two alternative electrodes (as calculated by considering the relative costs of the raw materials - see Supplementary Information for calculation) are - $£ 14 / \mathrm{m}^{2}$ (solution processed graphene) and $£ 520 / \mathrm{m}^{2}$ (solution processed platinum), meaning that the printed graphene electrode represents $\sim 97.3 \%$ reduction in materials cost.

The dye-adsorbed $\mathrm{TiO}_{2}$ electrode and the platinum or graphene counter electrode are assembled into a sandwich-type cell with a $60 \mu \mathrm{m}$ Surlyn thermoplastic film (Solaronix) to separate the photoanode and the counter electrode. An Iodolyte Z-50 (Solaronix) electrolyte solution $\left(\mathrm{I}^{-} / \mathrm{I}_{3}{ }^{-}\right)$is injected into the cell via the back-drilled hole in the counter electrode. The hole is then sealed using a Surlyn film to complete the device assembly.

\subsection{DSSC photoelectrochemical characterization}

An Oriel solar simulator with an AM 1.5 G filter is used as the for white-light source $\left(100 \mathrm{mWcm}^{-2}\right)$ for current-voltage characterization of the DSSCs. The light intensity is measured using a digital light meter. The short-circuit current density $\left(J_{s c}\right)$ is calculated by dividing the measured photocurrent by the actual active area $\left(\sim 0.36 \mathrm{~cm}^{2}\right)$ of the solar cell.

The photoelectrical parameters of the graphene ink and platinum counter electrodebased DSSCs sensitized by the natural and ruthenium dyes, under AM 1.5 (100 $\mathrm{mW} / \mathrm{cm}^{2}$ ) simulated solar illumination are shown in Fig. 6 and Table 2. The results are averaged from 3 devices, with $<5 \%$ standard deviation in values between them. The efficiency $(\eta)$ and fill factor (FF) are calculated as reported elsewhere [21]. Preliminary tests on the cells show that over a period of 24 hours of measurement, the devices remain stable with $<10 \%$ change in the conversion efficiency.

Cells fabricated with graphene inks and sensitized with natural dyes reached an efficiency $(\eta \%)$ of $0.9,>80 \%$ of that of platinum based natural dye cells $(\eta \sim 1.1 \%)$. Ruthenium based cells with graphene ink electrodes reached $(\eta \sim 3.0 \%) \sim 70 \%$ that of platinum based cells $(\eta \sim 4.4 \%)$. 
The open circuit voltage of the graphene natural dye cells yield $V_{o c}=580 \mathrm{mV}$, representing $\sim 83 \%$ of the platinum based cells. For the ruthenium dye based cells, $\mathrm{V}_{\text {oc }}=640 \mathrm{mV}$ was obtained, $\sim 98 \%$ of that for the platinum based cells $(650 \mathrm{mV})$. A positive shift in the iodide/tri-iodide redox energy level will increase in the open circuit voltage $\left(\mathrm{V}_{\mathrm{oc}}\right)$ and vice versa, thereby influencing the energy conversion efficiency of the cell $[46,79,80]$.

\begin{tabular}{|c|c|c|c|c|c|c|c|c|c|c|c|}
\hline \multicolumn{12}{|c|}{ Graphene/FTO Counter Electrode } \\
\hline \multirow{2}{*}{$\begin{array}{c}\text { Photosensitizer } \\
\text { Dye }\end{array}$} & \multirow{2}{*}{$\begin{array}{c}\text { Active } \\
\text { area } \\
\left(\mathrm{cm}^{2}\right)\end{array}$} & \multicolumn{3}{|c|}{$\mathbf{V}_{\text {oc }}$} & \multicolumn{2}{|c|}{$\mathbf{J}_{\mathbf{s c}}$} & \multicolumn{2}{|c|}{ FF } & \multicolumn{2}{|c|}{$\eta$} & \multirow{2}{*}{$\begin{array}{l}\text { n-ideal } \\
\text { factor }\end{array}$} \\
\hline & & (V) & $(\mathbf{m V})$ & $\begin{array}{c}\% \text { of } \\
P t\end{array}$ & $\left(\mathrm{~mA} / \mathrm{cm}^{2}\right)$ & $\begin{array}{c}\text { \% of } \\
\text { Pt }\end{array}$ & $(\%)$ & $\begin{array}{c}\text { \% of } \\
\mathrm{Pt}\end{array}$ & $(\%)$ & $\begin{array}{c}\text { \% of } \\
\text { Pt }\end{array}$ & \\
\hline P. glaucum & $\sim 0.36$ & 0.52 & 520 & 92.85 & 1.38 & 87.34 & 69.5 & 94.47 & 0.50 & 83.33 & 1.99 \\
\hline H. sabdariffa & $\sim 0.36$ & 0.50 & 500 & 92.59 & 1.16 & 52.25 & 62.6 & 82.83 & 0.4 & 44.44 & 2.68 \\
\hline C. pulcherrima & $\sim 0.36$ & 0.58 & 580 & 82.85 & 2.15 & 96.85 & 70.9 & 103.91 & 0.9 & 81.81 & 2.07 \\
\hline Ruthenizer N719 & $\sim 0.36$ & 0.64 & 640 & 98.46 & 7.44 & 76.46 & 62.0 & 88.77 & 3.0 & 68.18 & 3.52 \\
\hline \multicolumn{12}{|c|}{ Platinum Counter Electrode } \\
\hline P. glaucum & $\sim 0.36$ & 0.56 & 560 & & 1.58 & & 73.57 & & 0.6 & & 1.721 \\
\hline H. sabdariffa & $\sim 0.36$ & 0.54 & 540 & & 2.22 & & 75.57 & & 0.9 & & 1.48 \\
\hline C.pulcherrima & $\sim 0.36$ & 0.70 & 700 & & 2.28 & & 68.23 & & 1.1 & & 2.86 \\
\hline Ruthenizer N719 & $\sim 0.36$ & 0.65 & 650 & & 9.73 & & 69.84 & & 4.4 & & 2.45 \\
\hline
\end{tabular}

Table 2: Photoelectrical parameters of DSSCs fabricated with graphene and platinum counter electrodes 

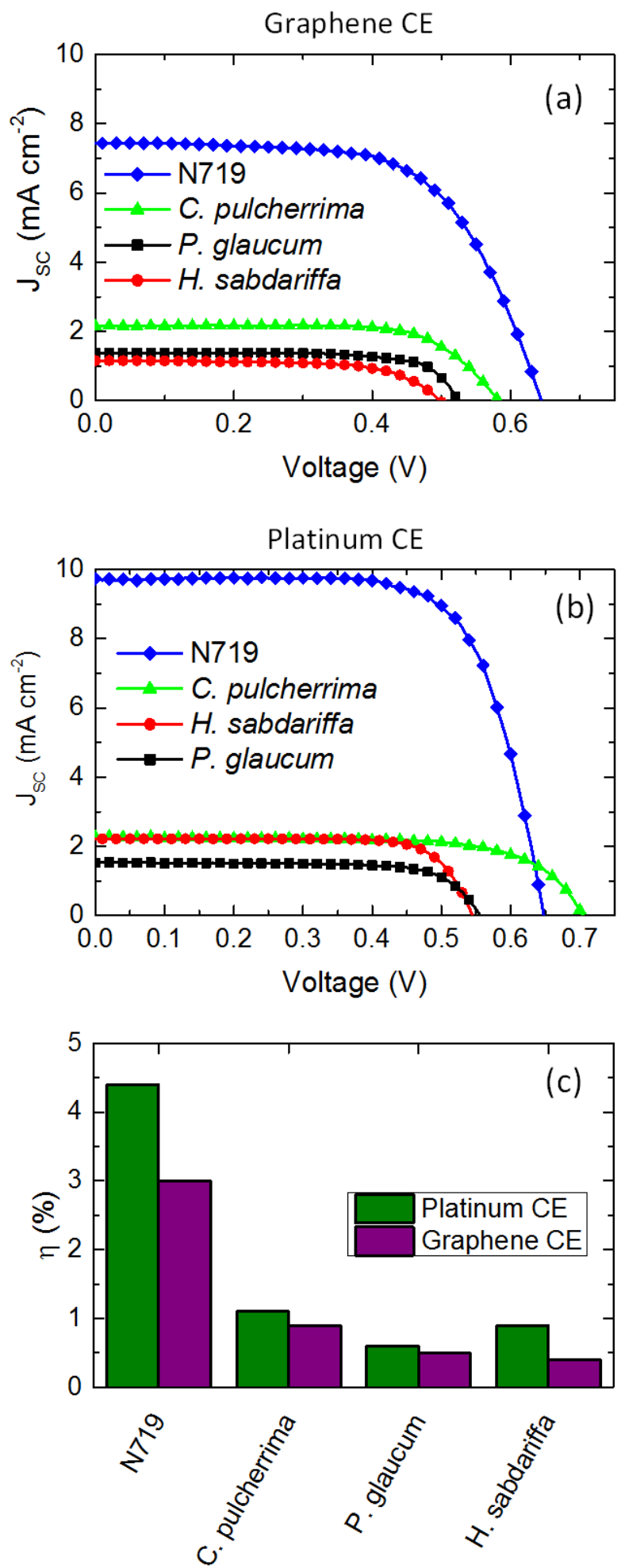

Figure 6 - Current-Voltage characteristic curves for (a) graphene ink CE based cells, (b) platinum CE based cells sensitized with (i) P. glaucum (square), (ii) H. sabdariffa (circle), (iii) C. pulcherrima (triangle), and (iv) Ruthenizer N719 (diamond) and (c) Comparison of the efficiencies for platinum and graphene ink based cells.

From the JV curves in Figure 6, it can be deduced that the graphene ink electrode cells sensitized with ruthenium dyes, exhibit a lower shunt resistance $\left(\mathrm{R}_{\mathrm{SH}}\right)$ and a higher 
series resistance $\left(R_{S E}\right)$ than the equivalent Pt-based cells. $R_{S H}$ and $R_{S E}$ can be calculated as [81]:

$$
\begin{aligned}
& R_{S H}=\frac{d V}{d J}_{V=0} \\
& R_{S E}=\frac{d V}{d J}_{J=0}
\end{aligned}
$$

This shows that $\mathrm{R}_{\mathrm{SH} ; \mathrm{Gr}} \sim 43.3 \Omega$, and $\mathrm{R}_{\mathrm{SE} ; \mathrm{Gr}} \sim 14.6 \mathrm{k} \Omega$, while $\mathrm{R}_{\mathrm{SH} ; \mathrm{Pt}} \sim 26.1 \Omega$, and $\mathrm{R}_{\mathrm{SE} ; \mathrm{Pt}}$ $\sim 23.9 \mathrm{k} \Omega$. Although this effect negligibly influences the $\mathrm{V}_{\mathrm{oc}}$, it influences the $\mathrm{J}_{\mathrm{sc}}$. The lower $\mathrm{R}_{\mathrm{SH}}$ for the graphene CEs could be attributed to factors such as current leakage paths on the graphene based electrodes, while the higher $\mathrm{R}_{\mathrm{SE}}$ could arise from the lower conductivity (i.e. higher sheet resistance) of the graphene electrode $(600 \Omega / \square)$ compared to that of the Pt based electrode $(15 \Omega / \square)$, or to slower electro-kinetics in graphene than in $\mathrm{Pt}[82,83]$.

From the obtained results, it can also be observed that the natural-dye-based DSSCs produce low efficiencies compared to the inorganic dye (N719) based cells. For a dye molecule to be an excellent photosensitizer in a DSSC, it must possess several carbonyl $(\mathrm{C}=\mathrm{O})$ or hydroxyl $(-\mathrm{OH})$ groups capable of chelating to the $\mathrm{Ti}^{(\mathrm{IV})}$ sites on the porous nanostructured $\mathrm{TiO}_{2}$ surface. The chemical adsorption of these dye molecules to the $\mathrm{TiO}_{2}$ nanoparticles in DSSCs occurs generally due to the condensation of the alcoholic-bound protons with the hydroxyl groups on the surface of the nanostructured $\mathrm{TiO}_{2}$ as well as the contribution of the chelating effect of the two nearest hydroxyl group towards $\mathrm{Ti}^{(\mathrm{IV})}$ sites on the semiconductor nanocrystalline layer $[28,60,84,85]$. It is also very important that the dye molecules do not aggregate ( $\pi-\pi$ stacking) on the photoelectrode $\left(\mathrm{TiO}_{2}\right)$ surface to avoid nonradiative decay of the excited state to the ground state, which often occurs with thicker films [86]. However, natural or organic dyes with good intermolecular $\pi-\pi *$ interactions help to achieve a closer packing of the dye molecules on the $\mathrm{TiO}_{2}$ surface and hence better protect the surface from contact with the electrolyte, thereby resulting in a high open-circuit voltage and hence high efficiencies [87]. The C. pulcherrima dye comprises carotenoids (Carotene and Xanthophyll) and anthocyanins while those from $H$. sabdariffa and P. glaucum have anthocyanins as their major components. The relatively high efficiency of $C$. pulcherrima dye based cells ( $\mathrm{Gr}$ and $\mathrm{Pt} \mathrm{CEs}$ ) could be attributed to a better intermolecular $\pi-\pi^{*}$ interactions in the dye arising from these carotenoids. We note 
that further investigation is required to fully understand the interactions and how they may be improved. In particular, it is likely that the efficiency could be improved further by the addition of different stabilizing functional group agents or binders to the dye molecules. This could be achieved through acid treatments $\left(\mathrm{CH}_{3} \mathrm{COOH}, \mathrm{HNO}_{3}\right.$ or $\mathrm{HCl}$ ) [88], or the addition of sugar molecules [89] or a co-adsorbent (e.g. chenodeoxycholic acid) [90].

Changes to the electrolyte and to the exfoliated graphene may also aid the DSSC efficiency. Cobalt polypyridine complex electrolytes in place of the iodide/triiodide may improve efficiencies especially in graphene based cells [20, 41]. Meanwhile, since the catalytic activity of the graphene is key to the device performance, increasing the density of the catalytic sites (e.g. by chemical functionalisation of the graphene) may enhance the efficiency, although a balance must be maintained to avoid excessively lowering the conductivity of the CE.

\section{Conclusions}

We have demonstrated low-cost, environmentally friendly alternatives for two key elements of DSSCs. Plant-extract dyes have been used as photosensitisers, in place of ruthenium-based dyes, where their simple extraction procedure, wide availability, and environmentally friendly nature make them promising alternative sources of sensitizers for DSSCs. Meanwhile, inkjet-printed graphene has been used as a counterelectrode in the place of platinum. A polymer-stabilised isopropanol-based graphene ink has been developed via UALPE of chemically pristine graphite. The ink is formulated for inkjet printing, where it shows consistent single-droplet jetting. This, combined with the low boiling point and low surface tension of the ink allows repeatable printing onto substrates including FTO/glass used for DSSC fabrication. The inkjet-printed graphene CEs exhibit promising electrocatalytic activity toward $\mathrm{I}_{3} / \mathrm{I}^{-}$ redox couple comparable to the Pt-based CEs. Further studies are now underway into the kinetics of the dye molecules, device structure and life-time of the fabricated solar cells. Overall, the low materials cost for the graphene electrodes $(\sim 2.7 \%$ of the equivalent solution processed $\mathrm{Pt}$ cost) makes them highly attractive for the development of low-cost DSSCs. These inkjet-printed graphene electrodes may additionally have wider applications in fully solution processed and printable perovskite solar cells, allowing their economic fabrication. 


\section{Acknowledgements}

Authors acknowledge support from CAPREX, Cambridge Africa Alborada Fund, The Royal Academy of Engineering through a fellowship (Graphlex), and the CarnegieUniversity of Ghana Next Generation of Africa Academics programme.

\section{References}

[1] Wang, X., Zhi, L., Tsao, N., Tomović, Ž., Li, J., Müllen, K. Transparent carbon films as electrodes in organic solar cells. Angew. Chemie. 2008;47; 2990-2

[2] Bae, S., Kim, H., Lee, Y., Xu, X., Park, J.-S., Zheng, Y., et al. Roll-to-roll production of 30-inch graphene films for transparent electrodes. Nat. Nanotechnol. 2010;5; 5748

[3] Yang, N., Zhai, J., Wang, D., Chen, Y., Jiang, L. Two-Dimensional Graphene Bridges Enhanced Photoinduced Charge Transport in Dye-Sensitized Solar Cells. ACS Nano. 2010;4; 887-94

[4] Wan, L., Wang, S., Wang, X., Dong, B., Xu, Z., Zhang, X., et al. Room-temperature fabrication of graphene films on variable substrates and its use as counter electrodes for dye-sensitized solar cells. Solid State Sci. 2011;13; 468-75

[5] Yuan, W., Zhou, Y., Li, Y., Li, C., Peng, H., Zhang, et al. The edge- and basal-planespecific electrochemistry of a single-layer graphene sheet. Sci. Rep 2013;3;2248

[6] Novoselov, K.S., Geim, A.K., Morozov, S. V, Jiang, D., Zhang, Y., Dubonos, S. V, et al. Electric field effect in atomically thin carbon films. Science 2004;306; 666-9

[7] Li, X., Cai, W., An, J., Kim, S., Nah, J., Yang, D., et al. Large-area synthesis of highquality and uniform graphene films on copper foils. Science $2009 ; 324 ; 1312-4$

[8] Stankovich, S., Dikin, D.A., Piner, R.D., Kohlhaas, K.A., Kleinhammes, A., Jia, Y., et al. Synthesis of graphene-based nanosheets via chemical reduction of exfoliated graphite oxide. Carbon 2007; 45;1558-65

[9] Coleman, J.N.: Liquid-phase exfoliation of nanotubes and graphene. Adv. Funct. Mater. $2009 ; 19 ; 3680-95$

[10] Coleman, J.N.: Liquid exfoliation of defect-free graphene. Acc. Chem. Res. 2013;46; $14-22$

[11] Hasan, T., Torrisi, F., Sun, Z., Popa, D., Nicolosi, V., Privitera, G., et al. Solution-phase exfoliation of graphite for ultrafast photonics. Phys. Status Solidi. 2010;247; 2953-7

[12] Hernandez, Y., Nicolosi, V., Lotya, M., Blighe, F.M., Sun, Z., De, S., et al. High-yield production of graphene by liquid-phase exfoliation of graphite. Nat. Nanotechnol. 
$2008 ; 3 ; 563-8$

[13] Mattevi, C., Kim, H., Chhowalla, M. A review of chemical vapour deposition of graphene on copper. J. Mater. Chem. 2011;21; 3324-34

[14] Kavan, L., Yum, J.H., Grätzel, M.: Optically transparent cathode for dye-sensitized solar cells based on graphene nanoplatelets. ACS Nano. 5, 165-172 (2011)

[15] Torrisi, F., Hasan, T., Wu, W., Sun, Z., Lombardo, A., Kulmala, T.S., et al. Inkjetprinted graphene electronics. ACS Nano 2012;6; 2992-3006

[16] Withers, F., Yang, H., Britnell, L., Rooney, A.P., Lewis, E., Felten, A. et al. Heterostructures produced from nanosheet-based inks. Nano Lett. 2014;14; 3987-92

[17] Howe, R.C.T., Hu, G., Yang, Z., Hasan, T. Functional inks of graphene, metal dichalcogenides and black phosphorus for photonics and (opto)electronics. Proc. SPIE 2015;9553; 95530R

[18] Secor, E.B., Prabhumirashi, P.L., Puntambekar, K., Geier, M.L., Hersam, M.C. Inkjet printing of high conductivity, flexible graphene patterns. J. Phys. Chem. Lett. 2013;4; $1347-51$

[19] Hutchings, I.M., Martin, G.D. Inkjet Technology for Digital Fabrication. Chichester U.K.: John Wiley and Sons 2012

[20] Yella, A., Lee, H.-W., Tsao, H.N., Yi, C., Chandiran, A.K., Nazeeruddin, M.K., et al. Porphyrin-Sensitized Solar Cells with Cobalt (II/III)-Based Redox Electrolyte Exceed 12 Percent Efficiency. Science 2011; 334;629-34

[21] Calogero, G., Bartolotta, A., Di Marco, G., Di Carlo, A., Bonaccorso, F. Vegetablebased dye-sensitized solar cells. Chem. Soc. Rev. 2015;44;3244-94

[22] O’Regan, B., Grätzel, M. A low-cost, high-efficiency solar cell based on dye-sensitized colloidal $\mathrm{TiO}_{2}$ films. Nature 1991;353;737-40

[23] Grätzel, M. Photoelectrochemical cells. Nature 2001;414;338-44

[24] Bisquert, J., Cahen, D., Hodes, G., Rühle, S., Zaban, A. Physical chemical principles of photovoltaic conversion with nanoparticulate, mesoporous dye-sensitized solar cells. J. Phys. Chem. B. 2004;108; 8106-18

[25] Calogero, G., Yum, J.-H., Sinopoli, A., Di Marco, G., Grätzel, M., Nazeeruddin, M.K. Anthocyanins and betalains as light-harvesting pigments for dye-sensitized solar cells. Sol. Energy. 2012;86;1563-75

[26] Hao, S., Wu, J., Huang, Y., Lin, J. Natural dyes as photosensitizers for dye-sensitized solar cell. Sol. Energy. 2006;80;209-14

[27] Matthews, D., Infelta, P., Grätzel, M. Calculation of the photocurrent-potential 
characteristic for regenerative, sensitized semiconductor electrodes. Sol. Energy Mater. Sol. Cells. 1996;44;119-55

[28] Tennakone, K., Kumara, G.R.R.A., Kumarasinghe, A.R., Sirimanne, P.M., Wijayantha, K.G.U. Efficient photosensitization of nanocrystalline $\mathrm{TiO}_{2}$ films by tannins and related phenolic substances. J. Photochem. Photobiol. A Chem. 1996;94;217-20

[29] Iha, N.Y.M. Supramolecular photochemistry and solar cells. An. Acad. Bras. Cienc. $2000 ; 72 ; 67-74$

[30]Solaronix Ruthenizer 535-bisTBA, http://shop.solaronix.com/ruthenizer-535-bistba.html

[31] Amao, Y., Komori, T. Bio-photovoltaic conversion device using chlorine-e ${ }_{6}$ derived from chlorophyll from Spirulina adsorbed on a nanocrystalline $\mathrm{TiO}_{2}$ film electrode. Biosens. Bioelectron. 2004;19;843-7

[32] Polo, A., Iha, N.Y.M. Blue sensitizers for solar cells: Natural dyes from Calafate and Jaboticaba. Sol. Energy Mater. Sol. Cells. 2006;90;1936-44

[33] Garcia, C.G., Polo, A.S., Murakami Iha, N.Y. Fruit extracts and ruthenium polypyridinic dyes for sensitization of $\mathrm{TiO}_{2}$ in photoelectrochemical solar cells. J. Photochem.

Photobiol. A Chem. 2003;160;87-91

[34] Andersen, Ø.M., Jordheim, M.: Anthocyanins. Encycl. Life Sci. Chichester U.K.: John Wiley and Sons 2010

[35] Kumara, G.R.A., Kaneko, S., Okuya, M., Onwona-Agyeman, B., Konno, A., Tennakone, K. Shiso leaf pigments for dye-sensitized solid-state solar cell. Sol. Energy Mater. Sol. Cells 2006;90;1220-6

[36] Cherepy, N.J., Smestad, G.P., Grätzel, M., Zhang, J.Z. Ultrafast Electron Injection: Implications for a Photoelectrochemical Cell Utilizing an Anthocyanin Dye-Sensitized $\mathrm{TiO}_{2}$ Nanocrystalline Electrode. J. Phys. Chem. B. 1997;101;9342-51

[37] Papageorgiou, N. Counter-electrode function in nanocrystalline photoelectrochemical cell configurations. Coord. Chem. Rev. 2004;248;1421-46

[38] Smestad, G., Bignozzi, C., Argazzi, R. Testing of dye sensitized $\mathrm{TiO}_{2}$ solar cells I: Experimental photocurrent output and conversion efficiencies. Sol. Energy Mater. Sol. Cells. 1994;32;259-72

[39] Fang, X., Ma, T., Guan, G., Akiyama, M., Kida, T., Abe, E. Effect of the thickness of the Pt film coated on a counter electrode on the performance of a dye-sensitized solar cell. J. Electroanal. Chem. 2004;570;257-63

[40] Olsen, E., Hagen, G., Eric Lindquist, S. Dissolution of platinum in methoxy propionitrile containing LiI/I $\mathrm{I}_{2}$. Sol. Energy Mater. Sol. Cells 2000;63;267-73 
[41] Roy-Mayhew, J.D., Bozym, D.J., Punckt, C., Aksay, I. A. Functionalized Graphene as a Catalytic Counter Electrode in Dye-Sensitized Solar Cells. ACS Nano 2010;4;6203-11

[42] Zhang, D.W., Li, X.D., Chen, S., Li, H.B., Sun, Z., Yin, X.J., et al. Graphene nanosheet counter-electrodes for dye-sensitized solar cells. 3rd International Nanoelectronics Conference (INEC). (Hong Kong, China): IEEE, 2010; p. 610-1

[43] Baker, J., Deganello, D., Gethin, D.T., Watson, T.M. Flexographic printing of graphene nanoplatelet ink to replace platinum as counter electrode catalyst in flexible dye sensitised solar cell. Mater. Res. Innov. 2014;18;86-90

[44] Peng, Y., Zhong, J., Wang, K., Xue, B., Cheng, Y.-B. A printable graphene enhanced composite counter electrode for flexible dye-sensitized solar cells. Nano Energy. 2013;2; $235-40$

[45] Kay, A., Grätzel, M. Low cost photovoltaic modules based on dye sensitized nanocrystalline titanium dioxide and carbon powder. Sol. Energy Mater. Sol. Cells 1996;44;99-117

[46] Ramasamy, E., Lee, W.J., Lee, D.Y., Song, J.S. Nanocarbon counterelectrode for dye sensitized solar cells. Appl. Phys. Lett. 2007;90;173103

[47] Saranya, K., Rameez, M., Subramania, A. Developments in conducting polymer based counter electrodes for dye-sensitized solar cells - An overview. Eur. Polym. J. 2015;66; $207-27$

[48] Wu, M., Lin, X., Hagfeldt, A., Ma, T. A novel catalyst of $\mathrm{WO}_{2}$ nanorod for the counter electrode of dye-sensitized solar cells. Chem. Commun. 2011;47;4535-7

[49] Kaniyoor, A., Ramaprabhu, S. Thermally exfoliated graphene based counter electrode for low cost dye sensitized solar cells. J. Appl. Phys. 2011;109;124308

[50] Wang, H., Leonard, S.L., Hu, Y.H. Promoting Effect of Graphene on Dye-Sensitized Solar Cells. Ind. Eng. Chem. Res. 2012;51;10613-20

[51] Cruz, R., Araújo, J.P., Andrade, L., Mendes, A. Transparent graphene-based counterelectrodes for iodide/triiodide mediated dye-sensitized solar cells. J. Mater. Chem. A. 2014;2; 2028-32

[52] Kwon, W., Kim, J.-M., Rhee, S.-W. Electrocatalytic carbonaceous materials for counter electrodes in dye-sensitized solar cells. J. Mater. Chem. A. 2013;1;3202-15

[53] Wu, M.-S., Zheng, Y.-J. Electrophoresis of randomly and vertically embedded graphenenanosheets in activated carbon film as a counter electrode for dye-sensitized solar cells. Phys. Chem. Chem. Phys. 2013;15;1782-7

[54] Roy-Mayhew, J.D., Aksay, I.A. Graphene Materials and Their Use in Dye-Sensitized 
Solar Cells. Chem. Rev. 2014;114;6323-48

[55] Murakami, T.N., Grätzel, M. Counter electrodes for DSC: Application of functional materials as catalysts. Inorganica Chim. Acta. 2008;361;572-80

[56] Santra, S., Hu, G., Howe, R.C.T., De Luca, A., Ali, S.Z., Udrea, F., Gardner, J.W., et al. CMOS integration of inkjet-printed graphene for humidity sensing. Sci. Rep. $2015 ; 5 ; 17374$

[57] Park, S., Ruoff, R. S. Chemical methods for the production of graphenes. Nat. Nanotechnol. 2009;4;217-24

[58] Rehm, J.M., McLendon, G.L., Nagasawa, Y., Yoshihara, K., Moser, J., Grätzel, M. Femtosecond Electron-Transfer Dynamics at a Sensitizing Dye-Semiconductor $\left(\mathrm{TiO}_{2}\right)$ Interface. J. Phys. Chem. 1996;100;9577-8

[59] Wongcharee, K., Meeyoo, V., Chavadej, S. Dye-sensitized solar cell using natural dyes extracted from rosella and blue pea flowers. Sol. Energy Mater. Sol. Cells 2007;91; $566-71$

[60] Dai, Q., Rabani, J. Photosensitization of nanocrystalline $\mathrm{TiO}_{2}$ films by pomegranate pigments with unusually high efficiency in aqueous medium. Chem. Commun. $2001 ; 2142-3$

[61] Delgado-Vargas, F., Jiménez, A.R., Paredes-López, O. Natural Pigments: Carotenoids, Anthocyanins, and Betalains - Characteristics, Biosynthesis, Processing, and Stability. Crit. Rev. Food Sci. Nutr. 2000;40;173-289

[62] Roy, S., Llewellyn, C., Egeland, E.S., Johnsen, G. eds. Phytoplankton Pigments. Cambridge, U.K.: Cambridge University Press 2011

[63] de Leeuw, D.M., Simenon, M.M.J., Brown, A. R., Einerhand, R.E.F. Stability of n-type doped conducting polymers and consequences for polymeric microelectronic devices. Synth. Met. 1997;87;53-9

[64] Bredas, J.L., Silbey, R., Boudreaux, D.S., Chance, R.R. Chain-length dependence of electronic and electrochemical properties of conjugated systems: polyacetylene, polyphenylene, polythiophene, and polypyrrole. J. Am. Chem. Soc. 1983;105;6555-9

[65] Hansen, C.M.: Hansen Solubility Parameters: A User's Handbook. Boca Raton FL: CRC Press, Inc. 2007

[66] Hernandez, Y., Lotya, M., Rickard, D., Bergin, S.D., Coleman, J.N. Measurement of multicomponent solubility parameters for graphene facilitates solvent discovery. Langmuir. 2010;26;3208-13

[67] Laws, C.L.: Thermophysical properties of chemicals and hydrocarbons. Norwich, NY: 
William Andrew Inc. 2008

[68] Fowkes, F.M. ed: Contact Angle, Wettability, and Adhesion. Washington, D.C.: American Chemical Society 1964

[69] Kipphan, H. ed: Handbook of Print Media: Technologies and Production Methods. Berlin, Germany: Springer 2001

[70] O’Neill, A., Khan, U., Nirmalraj, P.N., Boland, J., Coleman, J.N. Graphene dispersion and exfoliation in low boiling point solvents. J. Phys. Chem. C. 2011;115;5422-8

[71] Hasan, T., Tan, P.H., Bonaccorso, F., Rozhin, A.G., Scardaci, V., Milne, W.I., et al. Polymer-assisted isolation of single wall carbon nanotubes in organic solvents for optical-quality nanotube-polymer composites. J. Phys. Chem. C. 2008;112;20227-32

[72] Hasan, T., Scardaci, V., Tan, P., Rozhin, A.G., Milne, W.I., Ferrari, A.C. Stabilization and "debundling" of single-wall carbon nanotube dispersions in N-methyl-2-pyrrolidone (NMP) by polyvinylpyrrolidone (PVP). J. Phys. Chem. C. 2007;111;12594-602

[73] O’Connell, M.J., Boul, P., Ericson, L.M., Huffman, C., Wang, Y., Haroz, E., et al. Reversible water-solubilization of single-walled carbon nanotubes by polymer wrapping. Chem. Phys. Lett. 2001;342;265-71

[74] Bohren, C.F., Huffman, D.R.: Absorption and scattering of light by small particles. Weinheim, Germany: Wiley 1998

[75] Kravets, V.G., Grigorenko, A.N., Nair, R.R., Blake, P., Anissimova, S., Novoselov, K.S. et al. Spectroscopic ellipsometry of graphene and an exciton-shifted van Hove peak in absorption. Phys. Rev. B. 2010;81;155413

[76] Chou, K.-S., Chen, C.-C. Fabrication and characterization of silver core and porous silica shell nanocomposite particles. Microporous Mesoporous Mater. 2007;98;208-13

[77] Li, J., Ye, F., Vaziri, S., Muhammed, M., Lemme, M.C., Östling, M. Efficient Inkjet Printing of Graphene. Adv. Mater. 2013;25;3985-92 (2013)

[78] Gupta, A., Chen, G., Joshi, P., Tadigadapa, S., Eklund, P.C. Raman Scattering from High-Frequency Phonons in Supported n -Graphene Layer Films. Nano Lett. 2006;6; $2667-73$

[79] Zhou, C.-H., Yang, Y., Zhang, J., Xu, S., Wu, S.-J., Hu, H., et al. Enhanced electrochemical performance of the counterelectrode of dye sensitized solar cells by sandblasting. Electrochim. Acta. 2009;54;5320-5

[80] Dürr, M., Yasuda, A., Nelles, G. On the origin of increased open circuit voltage of dyesensitized solar cells using 4-tert-butyl pyridine as additive to the electrolyte. Appl. Phys. Lett. 2006;89;061110 
[81] Jiang, C.Y., Sun, X.W., Tan, K.W., Lo, G.Q., Kyaw, A.K.K., Kwong, D.L. Highbendability flexible dye-sensitized solar cell with a nanoparticle-modified $\mathrm{ZnO}$ nanowire electrode. Appl. Phys. Lett. 2008;92;143101

[82] Miettunen, K., Toivola, M., Hashmi, G., Salpakari, J., Asghar, I., Lund, P. A carbon gel catalyst layer for the roll-to-roll production of dye solar cells. Carbon. 2011;49;528-32

[83] Baker, J., McGettrick, J.D., Gethin, D.T., Watson, T.M. Impedance Characteristics of Transparent GNP-Pt Ink Catalysts for Flexible Dye Sensitized Solar Cells. J. Electrochem. Soc. 2015;162;H564-9

[84] Smestad, G.P., "Education and solar conversion: Demonstrating electron transfer", Sol. Energy Mater. Sol. Cells 1998; 55; 157.

[85] Meng, S., Ren, J., Kaxiras, E., Natural dyes adsorbed on $\mathrm{TiO}_{2}$ nanowire for photovoltaic applications: enhanced light absorption and ultrafast electron injection, Nano Lett. 2008; $8 ; 3266-3272$.

[86] Yum, J.-H., Chen, P., Graetzel, M., Nazeeruddin, M. K., Recent developments in solidstate dye-sensitized solar cells. ChemSusChem, 2008, 1, 699.

[87] Amaresh M., Markus K. Fischer, R., and Bauerle P., Metal-Free Organic Dyes for DyeSensitized Solar Cells: From Structure: Property Relationships to Design Rules Angew. Chem. Int. Ed. 2009; 48; $2474-2499$.

[88] Hee-Je K., Dong- Jo K., Karthick, S.N., Hemalatha, K.V., Justin Raj C., Youngson C.; Curcumin Dye Extracted from Curcuma longa L. Used as Sensitizers for Efficient DyeSensitized Solar Cells, Int. J. Electrochem. Sci., 8 (2013) 8320 - 8328

[89] F. Queiroz, C. Oliveira, O. Pinho, I.M. Ferreira, Degradation of Anthocyanins and Anthocyanidins in Blueberry Jams/Stuffed Fish, J. Agric. Food Chem. 2009;57; [22]; 10712-10717.

[90] Yinni W., Zhisheng W., Zhongwei A., Xinbing C., Pei, C., and Qianfeng, L., Highly Efficient Dye-sensitized Solar Cells by Co-sensitization of Organic Dyes and Coadsorbent Chenodeoxycholic Acid; Chin. J. Chem. 2014, 32, 474-478 


\section{Inkjet-printed graphene electrodes for dye-sensitized solar cells}

\section{Supplementary Information}

David Dodoo-Arhin, ${ }^{a, b}$ Richard C. T. Howe, ${ }^{a}$ Guohua Hu,${ }^{a}$ Yinghe Zhang, ${ }^{c}$ Pritesh Hiralal, ${ }^{d}$

Abdulhakeem Bello, ${ }^{e}$ Gehan Amaratunga, ${ }^{d}$ and Tawfique Hasan ${ }^{*}, a$

${ }^{a}$ Cambridge Graphene Centre, University of Cambridge, 9 JJ Thomson Avenue, Cambridge, CB3 0FA, UK.

${ }^{b}$ Department of Material Science and Engineering, University of Ghana, P. O. Box Lg 77, Accra-Legon, Ghana.

${ }^{c}$ Faculty of Science and Engineering, Waseda University, Tokyo, Japan.

${ }^{\mathrm{d}}$ Department of Engineering, University of Cambridge, $9 \mathrm{JJ}$ Thomson Avenue, Cambridge, CB3 0FA, UK.

${ }^{\mathrm{e}}$ Department of Physics, University of Pretoria, Pretoria 0028, South Africa.

*Corresponding author-e-mail: th270@cam.ac.uk

\section{FTIR measurements of natural dyes}

Chemical adsorption of the natural dye molecules to the $\mathrm{TiO}_{2}$ nanoparticles in a DSSC occurs due to condensation of the alcoholic-bound protons with the hydroxyl groups on the surface of the nanostructured $\mathrm{TiO}_{2}[1]$ and the chelating effect of the two nearest hydroxyl groups toward the $\mathrm{Ti}^{(\mathrm{IV})}$ sites $[1-4]$. To determine the presence of the functional groups in our dye extracts, transmission Fourier transform infrared spectroscopy (FTIR) spectra data are recorded on a Vertex 70v (Bruker) spectrometer in the 4000-400 $\mathrm{cm}^{-1}$ range with $4 \mathrm{~cm}^{-1}$ resolution. The sample compartment is evacuated during acquisition. The contact between the sample and the diamond ATR crystal is $2 \mathrm{~mm}$ in diameter. Figure S1 shows the FTIR spectra of the extracted dry natural dyes. The strong and broad bands at $\sim 3000-3700 \mathrm{~cm}^{-1}$ are due to the $-\mathrm{OH}$ stretching vibration of free hydroxyl groups in anthocyanin and residual ethanol [5]. The peaks at $\sim 2920$ and $\sim 2850 \mathrm{~cm}^{-1}$ correspond to the $-\mathrm{CH}$ stretching mode, attributed to the anthocyanin pigments $[5,6]$. The peak at $\sim 1724 \mathrm{~cm}^{-1}$ corresponds to the $\mathrm{C}=\mathrm{O}$ stretching vibration of a partial quinonoidal form of the anthocyanin molecules in the dye [7]. The spectral region between 1550 to $1700 \mathrm{~cm}^{-1}$ shows infrared absorption of the double bond $(\mathrm{C}=\mathrm{C})$ stretching vibration, correlated with the stretching of the aromatic $\mathrm{C}=\mathrm{C}$ in anthocyanin [7]. The bands at $\sim 1495$ and $1335 \mathrm{~cm}^{-1}$ correspond to the vibrational mode of $\mathrm{C}-\mathrm{O}$ elongation of the alcohol and phenol groups. The intense bands at $\sim 1066 \mathrm{~cm}^{-1}$ are attributed to the $\mathrm{C}-\mathrm{O}-\mathrm{C}$ vibrational modes of acidic and 
carbohydrate groups. Thus, FTIR measurements confirm the presence of the functional groups in the dye extracts.
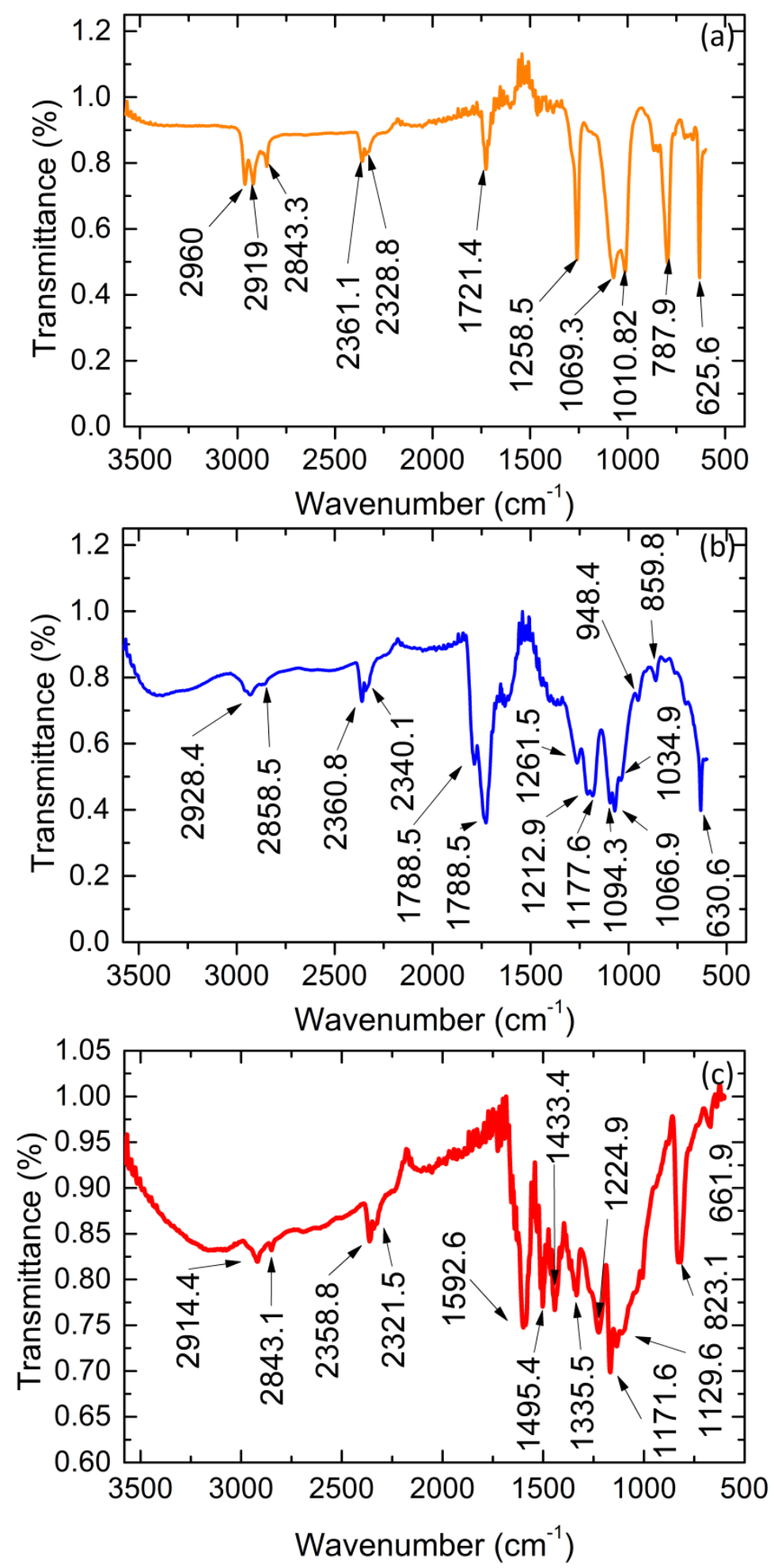

Figure S1 - FTIR spectra of (a) C. pulcherimma dye, (b) H. sabdariffa dye, (c) P. glaucum dye 


\section{Calculation of relative costs:}

\begin{tabular}{|c|c|c|c|c|c|}
\hline Material & \multicolumn{2}{|l|}{ Volume required (L) } & \multicolumn{2}{c|}{ Cost (£) } & Cost \\
& \multicolumn{2}{|l}{} & \multicolumn{2}{l}{} & \\
\cline { 2 - 5 } & $\mathrm{CE}$ & $1 \mathrm{~m}^{2}$ & $\mathrm{CE}$ & $1 \mathrm{~m}^{2}$ & \\
\hline Platinum & $60 \times 10^{-6}$ & 1.7 & 0.02 & 530 & - \\
\hline Graphene & $10 \times 10^{-6}$ & 0.3 & 0.001 & 15 & $97.3 \%$ \\
\hline
\end{tabular}

Cost of $1 \mathrm{~L}$ of graphene ink $=£ 50.43$

1L Isopropanol - $£ 50.20$ (based on $£ 50.20 / 1$ litre - Sigma Aldrich product 673773-1L)

0.15g PVP - $£ 0.03$ (based on $£ 19.80 / 100 \mathrm{~g}$ - Sigma Aldrich product PVP10-100G)

$10 \mathrm{~g}$ graphite - $£ 0.20$ (based on $£ 41.10 / 2.5 \mathrm{~kg}$ - Sigma Aldrich product $332461-2.5 \mathrm{KG}$ )

Cost of $1 \mathrm{~L}$ of $\mathrm{Pt}\left(10 \mathrm{mM} \mathrm{H}_{2} \mathrm{PtCl}_{6}=£ 311.70\right)$

1L Isopropanol - $£ 50.20$ (based on $£ 50.20 / 1$ litre - Sigma Aldrich product 673773-1L)

$5.18 \mathrm{~g} \mathrm{H}_{2} \mathrm{PtCl}_{6}-£ 261.50$ (based on 252.50/5g - Sigma Aldrich product P5775-5G)

\section{References}

1. Tennakone, K., Kumara, G.R.R.A., Kumarasinghe, A.R., Sirimanne, P.M., Wijayantha, K.G.U. Efficient photosensitization of nanocrystalline $\mathrm{TiO}_{2}$ films by tannins and related phenolic substances. J. Photochem. Photobiol. A Chem. 1996;94;217-20

2. Garcia, C.G., Polo, A.S., Murakami Iha, N.Y. Fruit extracts and ruthenium polypyridinic dyes for sensitization of $\mathrm{TiO}_{2}$ in photoelectrochemical solar cells. J. Photochem. Photobiol. A Chem. 2003;160;87-91

3. Meng S., Ren J., Kaxiras E. Natural dyes adsorbed on $\mathrm{TiO}_{2}$ nanowire for photovoltaic applications: enhanced light absorption and ultrafast electron injection. Nano Lett. 2008;8;3266-72

4. Dai Q, Rabani J. Photosensitization of nanocrystalline $\mathrm{TiO}_{2}$ films by anthocyanin dyes. J Photochem Photobiol A Chem. 2002;148;17-24 
5. Bunghez I.R., Raduly M., Doncea S., Aksahin, I. and Ion, R.M. Lycopene determination in tomatoes by different spectral techniques (UV-VIS, FTIR and HPLC). Dig J Nanomater Biostructures 2011;6:1349-56

6. Lóránd T., Deli J., Molnár P., Tóth G. FT-IR Study of Some Carotenoids. Helv Chim Acta 2002;85;1691-7

7. Luo P, Niu H, Zheng G, et al. From salmon pink to blue natural sensitizers for solar cells: Canna indica L., Salvia splendens, cowberry and Solanum nigrum L. Spectrochim Acta Part A Mol Biomol Spectrosc 2009;74;936-42 